\title{
The modified Ishikawa iteration process with errors in CAT(0) spaces
}

\author{
Sajad Ranjbar
}

\begin{abstract}
In this article, $\Delta$-convergence and strong convergence of the modified Ishikawa iteration process with errors are established for continuous mappings of asymptotically nonexpansive type in CAT(0) spaces. Our results extend and improve the previous results given by many authors.
\end{abstract}

\section{Introduction and Preliminaries}

Let $C$ be a closed convex subset of a metric space $(X, d)$. A mapping $T: C \rightarrow C$ is said to be nonexpansive if and only if

$$
d(T x, T y) \leq d(x, y), \quad \forall x, y \in C .
$$

A mapping $T: C \rightarrow C$ is called asymptotically nonexpansive if and only if there exists a sequence $\left\{k_{n}\right\}$ of positive real numbers with $k_{n} \longrightarrow 1$ as $n \longrightarrow \infty$ for which

$$
d\left(T^{n} x, T^{n} y\right) \leq k_{n} d(x, y), \quad \text { for all } x, y \in C .
$$

A mapping $T: C \rightarrow C$ is of asymptotically nonexpansive type if and only if $T$ satisfies

$$
\lim \sup _{n \rightarrow \infty} \sup _{y \in C}\left(d\left(T^{n} x, T^{n} y\right)-d(x, y)\right) \leq 0 \quad \forall x \in C,
$$

Key Words: Mapping of asymptotically nonexpansive type, Fixed point, $\Delta$-convergence, CAT(0) space, Modified Ishikawa iteration.

2010 Mathematics Subject Classification: Primary 47H10; Secondary 47H09, 26A18.

Received: 12.01 .2020$.

Accepted: 20.02.2020 
and $T^{n}$ is continuous for some $n \geq 1$.

We denote the set of fixed points of $T$ with $F(T)$; that is, Fix $(T)=\{x \in$ $C: T x=x\}$.

It is clear that nonexpansive and asymptotically nonexpansive mappings are mappings of asymptotically nonexpansive type.

Bruck et al. [3] introduced the notion of mappings which are asymptotically nonexpansive in the intermediate sense (continuous mappings of asymptotically nonexpansive type) and obtained the weak convergence theorems of averaging iteration for mappings of asymptotically nonexpansive type in the intermediate sense in uniformly convex Banach space with the Opial property. Since then many authors have studied existence and convergence theorems of fixed points for these two classes of mappings in Banach spaces, for example, $\mathrm{Xu}$ [23], Kaczor [15], Rhoades [20], etc.

Let $\mathrm{C}$ be a nonempty closed subset of a Hilbert space $\mathrm{H}$ and let $T: C \longrightarrow$ $C$ be an asymptotically nonexpansive mapping. The modified KrasnoselskiMann iteration process

$$
x_{n+1}=\alpha_{n} T^{n} x_{n}+\left(1-\alpha_{n}\right) x_{n}, \quad \forall n \geq 1,
$$

was studied by Schu [21] in Hilbert spaces, where $\left\{\alpha_{n}\right\} \subset[0,1]$ and $x_{1} \in C$.

Tan and $\mathrm{Xu}[22]$ extended the result of Schu to uniformly convex Banach spaces for the modified Ishikawa iteration process

$$
\begin{gathered}
y_{n}=s_{n} T^{n} x_{n}+\left(1-s_{n}\right) x_{n}, \\
x_{n+1}=t_{n} T^{n} y_{n}+\left(1-t_{n}\right) x_{n},
\end{gathered}
$$

where $\left\{t_{n}\right\},\left\{s_{n}\right\}$ are sequences in $[0,1]$ and $x_{1} \in C$.

Now, we introduce CAT $(0)$ spaces. Let $(X, d)$ be a metric space and $x, y \in$ $X$. A geodesic path joining $x$ to $y$ is an isometry $c:[0, d(x, y)] \longrightarrow X$ such that $c(0)=x, c(d(x, y))=y$. The image of a geodesic path joining $x$ to $y$ is called a geodesic segment between $x$ and $y$. When it is unique, this geodesic segment is denoted by $[x, y]$. The space $(X, d)$ is said to be a geodesic space if and only if every two points of $X$ are joined by a geodesic path, and $X$ is said to be uniquely geodesic if and only if there is exactly one geodesic path joining $x$ and $y$ for each $x, y \in X$. A subset $Y \subseteq X$ is said to be convex if $Y$ includes every geodesic segment joining of any two its points.

A geodesic triangle $\triangle\left(x_{1}, x_{2}, x_{3}\right)$ in a geodesic space $X$ consists of three points $x_{1}, x_{2}, x_{3}$ in $X$ (the vertices of $\triangle$ ) and a geodesic segment between each pair of vertices. A comparison triangle for the geodesic triangle $\triangle\left(x_{1}, x_{2}, x_{3}\right)$ is the triangle $\bar{\triangle}\left(\overline{x_{1}}, \overline{x_{2}}, \overline{x_{3}}\right)$ in the Euclidean plane $\mathbb{R}^{2}$ such that

$$
d_{\mathbb{R}^{2}}\left(\overline{x_{i}}, \overline{x_{j}}\right)=d\left(x_{i}, x_{j}\right) \text { for } i, j \in\{1,2,3\} .
$$


A geodesic space $X$ is a $\mathrm{CAT}(0)$ space if for each geodesic triangle $\triangle$ in $X$ and its comparison triangle $\bar{\triangle}$ in $\mathbb{R}^{2}$, the $\mathrm{CAT}(0)$ inequality

$$
d(x, y) \leq d_{\mathbb{R}^{2}}(\bar{x}, \bar{y})
$$

is satisfied for all $x, y \in \triangle$ and $\bar{x}, \bar{y} \in \bar{\triangle}$. The meaning of the $\mathrm{CAT}(0)$ inequality is that a geodesic triangle in $X$ is at least thin as its comparison triangle in the Euclidean plane. It is well known that CAT(0) spaces are uniquely geodesic spaces.

There are several examples of $\mathrm{CAT}(0)$ spaces among metric structures. For example, any complete simply connected Riemannian manifold with nonpositive sectional curvature is a $\mathrm{CAT}(0)$ space. Other examples include pre-Hilbert spaces (see [1]), $\mathbb{R}$-trees (see [10]), Euclidean buildings (see [2]), complex Hilbert ball with a hyperbolic metric (see [8]). For a thorough discussion of these spaces and their fundamental role that play in geometry, we refer the reader to Bridson and Haefliger [1].

Fixed-point theory on CAT(0) spaces was first studied by Kirk (see $[12,13]$ ). He showed that every nonexpansive (single-valued) mapping defined on a bounded, closed and convex subset of a complete CAT(0) space always has a fixed point. Since then, the fixed-point theory for single-valued and multivalued mappings in CAT(0) spaces has rapidly been developed. It is worth to mention that fixed-point theorems in $\operatorname{CAT}(0)$ spaces (specially in $\mathbb{R}$-trees) can be applied to graph theory, biology, and computer science.

In this article, we write $(1-t) x \oplus t y$ for the unique point $z$ in the geodesic segment joining from $x$ to $y$ such that $d(z, x)=t d(x, y), d(z, y)=(1-t) d(x, y)$. If $X$ is a $\operatorname{CAT}(0)$ space and $x, y \in X$ then $[x, y]=\{(1-t) x \oplus t y: t \in[0,1]\}$ and subset $C$ of $X$ is convex if $[x, y] \subseteq C$, for all $x, y \in C$.

Lemma 1.1. [6] Let $(X, d)$ be a $C A T(0)$ space. Then, for all $x, y, z \in X$ and all $t \in[0,1]:$

(1) $\quad d^{2}(t x \oplus(1-t) y, z) \leq t d^{2}(x, z)+(1-t) d^{2}(y, z)-t(1-t) d^{2}(x, y)$,

(2) $d(t x \oplus(1-t) y, z) \leq t d(x, z)+(1-t) d(y, z)$.

In addition, by using (1), we have

$$
d(t x \oplus(1-t) y, t x \oplus(1-t) z) \leq(1-t) d(y, z) .
$$

We now give the concept of $\Delta$-convergence and collect some of its basic properties.

Let $\left\{x_{n}\right\}$ be a bounded sequence in a $\operatorname{CAT}(0)$ space $X$. For $x \in X$, we set

$$
r\left(x,\left\{x_{n}\right\}\right)=\limsup _{n \rightarrow \infty} d\left(x, x_{n}\right) .
$$

The asymptotic radius $r\left(\left\{x_{n}\right\}\right)$ of $\left\{x_{n}\right\}$ is given by 


$$
r\left(\left\{x_{n}\right\}\right)=\inf \left\{r\left(x,\left\{x_{n}\right\}\right): x \in X\right\} .
$$
by

The asymptotic radius $r_{C}\left(\left\{x_{n}\right\}\right)$ of $\left\{x_{n}\right\}$ with respect to $C \subseteq X$ is given

$$
r_{C}\left(\left\{x_{n}\right\}\right)=\inf \left\{r\left(x,\left\{x_{n}\right\}\right): x \in C\right\} .
$$

The asymptotic center $A\left(\left\{x_{n}\right\}\right)$ of $\left\{x_{n}\right\}$ is the set

$$
A\left(\left\{x_{n}\right\}\right)=\left\{x \in X: r\left(x,\left\{x_{n}\right\}\right)=r\left(\left\{x_{n}\right\}\right)\right\} .
$$

The asymptotic center $A_{C}\left(\left\{x_{n}\right\}\right)$ of $\left\{x_{n}\right\}$ with respect to $C \subseteq X$ is the set

$$
A_{C}\left(\left\{x_{n}\right\}\right)=\left\{x \in C: r\left(x,\left\{x_{n}\right\}\right)=r_{C}\left(\left\{x_{n}\right\}\right)\right\} .
$$

Recall that a bounded sequence $\left\{x_{n}\right\}$ in $X$ is regular if and only if $r\left(\left\{x_{n}\right\}\right)=$ $r\left(\left\{u_{n}\right\}\right)$ for every subsequence $\left\{u_{n}\right\}$ of $\left\{x_{n}\right\}$.

Lemma 1.2. [5] If $\left\{x_{n}\right\}$ is a bounded sequence in a complete CAT(0) space $X$ and $C$ is a closed and convex subset of $X$, then there exists a unique point $u \in C$ such that

$$
r\left(u,\left\{x_{n}\right\}\right)=\inf _{x \in C} d\left(x, x_{n}\right)
$$

The following lemma is obtained by Lemma 1.2.

Lemma 1.3. Let $\left\{x_{n}\right\}, C$ and $X$ be as in Lemma 1.2. Then, $A\left(\left\{x_{n}\right\}\right)$ and $A_{C}\left(\left\{x_{n}\right\}\right)$ are singletons.

Lemma 1.4. [4] If $C$ is a closed and convex subset of $X$ and $\left\{x_{n}\right\}$ is a bounded sequence in $C$, then the asymptotic center of $\left\{x_{n}\right\}$ is in $C$.

Lemma 1.5. [6] If $\left\{x_{n}\right\}$ is a bounded sequence in a CAT(0) space $X$ with $A\left(\left\{x_{n}\right\}\right)=\{x\}$ and $\left\{u_{n}\right\}$ is a subsequence of $\left\{x_{n}\right\}$ with $A\left(\left\{u_{n}\right\}\right)=\{u\}$ and the sequence $\left\{d\left(x_{n}, u\right)\right\}$ converges, then $x=u$.

Lim [16] introduced the concept of " $\Delta$ - convergence" in a general metric space. Kirk and Panyanak [14] specialized Lim's concept to CAT(0) spaces.

Definition 1.6. $[14,16]$ A sequence $\left\{x_{n}\right\}$ in $X$ is $\Delta$-convergent to $x \in X$ if and only if $x$ is the unique asymptotic center of $\left\{u_{n}\right\}$ for every subsequence $\left\{u_{n}\right\}$ of $\left\{x_{n}\right\}$. In this case, we write $\Delta-\lim _{n \rightarrow \infty} x_{n}=x$ and call $x$ the $\Delta$-limit of $\left\{x_{n}\right\}$.

Lemma 1.7. [14] Every bounded sequence in a complete CAT(0) space always has a $\Delta$-convergent subsequence. 
Also, a notion of convergence in $\mathrm{CAT}(0)$ spaces was introduced by Hussain and Khamsi [9]. As follows,

Let $\left\{x_{n}\right\}$ be a bounded sequence in a $\mathrm{CAT}(0)$ space $X$ and $C$ be a closed convex subset of $X$ which contains $\left\{x_{n}\right\}$. We denote the notation

$$
\left\{x_{n}\right\} \rightarrow w \text { if and only if } \phi(w)=\inf _{x \in C} \phi(x)
$$

where $\phi(x)=\limsup _{n \rightarrow \infty} d\left(x_{n}, x\right)$.

Lemma 1.8. [24] Let $X$ be a complete $C A T(0)$ space and $C$ be a nonempty, bounded, closed and convex subset of $X$. Then every mapping of asymptotically nonexpansive type $T: C \rightarrow C$ has a fixed point.

Lemma 1.9. [24] Let $X$ be a complete $C A T(0)$ metric space, $C$ be a nonempty, bounded, closed and convex subset of $X, T: C \rightarrow C$ be a continuous mapping of asymptotically nonexpansive type and $\left\{x_{n}\right\} \subset C$ be a sequence such that $\lim _{n \rightarrow \infty} d\left(x_{n}, T x_{n}\right)=0$ and $x_{n} \rightarrow w$.Then, $T w=w$.

The following Lemma shows the connection between " $\rightarrow$ " and $\Delta$-convergence.

Lemma 1.10. [17] Let $\left\{x_{n}\right\}$ be a bounded sequence in a CAT(0) space $X$ and $C$ be a closed and convex subset of $X$ which contains $\left\{x_{n}\right\}$. Then,

(1) $\Delta-\lim _{n \rightarrow \infty} x_{n}=x$ implies $x_{n} \rightarrow x$;

(2) if $\left\{x_{n}\right\}$ is regular, then $x_{n} \rightarrow x$ implies $\Delta-\lim _{n \rightarrow \infty} x_{n}=x$.

Easily, we can obtain the following corollary from Lemma 1.9 and Lemma 1.10 .

Corollary 1.11. Let $X$ be a complete $C A T(0)$ metric space, $C$ be a nonempty, bounded, closed and convex subset of $X, T: C \rightarrow C$ be a continuous mapping of asymptotically nonexpansive type and $\left\{x_{n}\right\} \subset C$ be a sequence such that $\lim _{n \rightarrow \infty} d\left(x_{n}, T x_{n}\right)=0$ and $\Delta-\lim _{n \rightarrow \infty} x_{n}=w$. Then, $T w=w$.

Lemma 1.12. [24] Let $X$ be a complete $C A T(0)$ space, $C$ be a closed and convex subset of $X$ and $T: C \rightarrow C$ be a continuous mapping of asymptotically nonexpansive type. Suppose that $\left\{x_{n}\right\}$ is a bounded sequence in $C$ such that $\lim _{n \rightarrow \infty} d\left(x_{n}, T x_{n}\right)=0$ and $d\left(x_{n}, p\right)$ converges for each $p \in F i x(T)$, then $\omega_{w}\left(x_{n}\right) \subset$ Fix $(T)$. Here $\omega_{w}\left(x_{n}\right)=\bigcup A\left(\left\{u_{n}\right\}\right)$, where the union is taken over all subsequences $\left\{u_{n}\right\}$ of $\left\{x_{n}\right\}$. Moreover, $\omega_{w}\left(x_{n}\right)$ consists of exactly one point.

Let $C$ be a nonempty, closed and convex subset of a CAT(0) space $X$ and $T: C \longrightarrow C$ be an asymptotically nonexpansive mapping. $\Delta$-convergence of the modified Krasnoselski-Mann iteration process

$$
x_{n+1}=\alpha_{n} T^{n} x_{n} \oplus\left(1-\alpha_{n}\right) x_{n}, \quad \forall n \geq 1,
$$


was studied by Nanjaras and Panyanak [17] in CAT(0) spaces, where $\left\{\alpha_{n}\right\} \subset$ $[0,1]$ and $x_{1} \in C$. Zhang and Cui [24] extended the results of Nanjaras and Panyanak [17] and obtained the existence of fixed points, demiclosed principle and $\Delta$-convergence of the sequence generated by (1.1) for continuous mapping of asymptotically nonexpansive type. On the other hand, Panyanak and Laokul [19] introduced the modified Ishikawa iteration process in CAT(0) spaces $X$, as follow,

$$
\left\{\begin{array}{l}
y_{n}=s_{n} T x_{n} \oplus\left(1-s_{n}\right) x_{n}, \\
x_{n+1}=t_{n} T y_{n} \oplus\left(1-t_{n}\right) x_{n}
\end{array}\right.
$$

where $T$ is a nonexpansive mapping of $C \subset X$ to itself, $\left\{t_{n}\right\},\left\{s_{n}\right\} \subset[0,1]$ and $x_{1} \in C$. They proved $\Delta$-convergence of (1.2) under certain appropriate assumptions on $C \subset X,\left\{t_{n}\right\}$ and $\left\{s_{n}\right\}$.

In this article, we consider the modified Ishikawa iteration with errors for continuous mappings of asymptotically nonexpansive type in CAT(0) spaces and prove the strong convergence and $\Delta$-convergence theorems of the sequence generated by the modified Ishikawa iteration with errors. Our results extend the results of Nanjaras and Panyanak [17], Zhang and Cui [24] and Panyanak and Laokul [19] and some other results in the literatures.

Lemma 1.13. [18] Let $\left\{\alpha_{n}\right\}_{n \geq 1},\left\{\beta_{n}\right\}_{n \geq 1}$ and $\left\{\gamma_{n}\right\}_{n \geq 1}$ be non-negative sequences satisfying

$$
\alpha_{n+1} \leq\left(1+\gamma_{n}\right) \alpha_{n}+\beta_{n}, n \geq 1, \sum_{n=1}^{\infty} \gamma_{n}<\infty, \sum_{n=1}^{\infty} \beta_{n}<\infty .
$$

Then $\lim \alpha_{n}$ exists. Moreover, if $\liminf \operatorname{in}_{n \rightarrow \infty} \alpha_{n}=0$, then $\lim \alpha_{n}=0$.

Lemma 1.14. [17] Let $X$ be a complete $C A T(0)$ space and $x \in X$. Suppose $\left\{t_{n}\right\}$ is a sequence in $[b, c]$ for some $b, c \in(0,1)$ and $\left\{x_{n}\right\},\left\{y_{n}\right\}$ are sequences in $X$ such that $\limsup _{n \rightarrow \infty} d\left(x_{n}, x\right) \leq r$, $\limsup _{n \rightarrow \infty} d\left(y_{n}, x\right) \leq r$, and $\lim _{n \rightarrow \infty} d\left(\left(1-t_{n}\right) x_{n} \oplus t_{n} y_{n}, x\right)=r$ for some $r \geq 0$. Then $\lim _{n \rightarrow \infty} d\left(x_{n}, y_{n}\right)=$ 0 .

\section{Main Results}

In the following, we introduce the modified Ishikawa iteration process with errors for continuous mappings of asymptotically nonexpansive type at CAT(0) spaces setting and establish the strong convergence and $\Delta$-convergence theorems of the sequence generated by the modified Ishikawa iteration with errors. 
Definition 2.1. Let $X$ be a complete $\mathrm{CAT}(0)$ space, $C$ be a nonempty, bounded, closed and convex subset of $X$ and $T: C \rightarrow C$ be a continuous mapping of asymptotically nonexpansive type. Suppose that $x_{1} \in C$ is arbitrary chosen, the modified Ishikawa iteration process $\left\{x_{n}\right\}$ with errors for continuous mappings of asymptotically nonexpansive type is iteratively generated by the following algorithm:

Step (1): Take $u_{n}=s_{n} T^{n} x_{n} \oplus\left(1-s_{n}\right) x_{n}, \quad \forall n \geq 1$.

Step (2): Choose $y_{n} \in C$ such that $d\left(y_{n}, u_{n}\right) \leq a_{n}$, where $\left\{a_{n}\right\}$ is a sequence of nonnegative real numbers.

Step (3): Take $v_{n}=t_{n} T^{n} y_{n} \oplus\left(1-t_{n}\right) x_{n}, \quad \forall n \geq 1$.

Step (4): Choose $x_{n+1} \in C$ such that $d\left(v_{n}, x_{n+1}\right) \leq b_{n}$, where $\left\{b_{n}\right\}$ is a sequence of nonnegative real numbers.

Step (5): Return to step (1).

Where $\left\{t_{n}\right\},\left\{s_{n}\right\}$ are sequences in $[0,1], \sum_{n=1}^{\infty} a_{n}<\infty$ and $\sum_{n=1}^{\infty} b_{n}<\infty$.

Lemma 2.2. Let $X$ be a complete $C A T(0)$ space, $C$ be a nonempty, bounded, closed and convex subset of $X$ and $T: C \rightarrow C$ be a continuous mapping of asymptotically nonexpansive type. Put

$$
c_{n}=\max \left\{0, \sup _{x, y \in C}\left\{d\left(T^{n} x, T^{n} y\right)-d(x, y)\right\}\right\} .
$$

If $\sum_{n=1}^{\infty} c_{n}<\infty$ and $\left\{x_{n}\right\}$ is given by definition 2.1, then $\lim _{n \rightarrow \infty} d\left(x_{n}, p\right)$ exists for any $p \in$ Fix $(T)$.

Proof. By using Lemma 1.8, let $p \in F(T)$. Then,

$d\left(x_{n+1}, p\right) \leq d\left(x_{n+1}, v_{n}\right)+d\left(v_{n}, p\right)$

$\leq b_{n}+t_{n} d\left(T^{n} y_{n}, p\right)+\left(1-t_{n}\right) d\left(x_{n}, p\right)$

$\leq b_{n}+t_{n}\left[d\left(y_{n}, p\right)+c_{n}\right]+\left(1-t_{n}\right) d\left(x_{n}, p\right)$

$\leq b_{n}+t_{n} d\left(y_{n}, u_{n}\right)+t_{n} d\left(u_{n}, p\right)+t_{n} c_{n}+\left(1-t_{n}\right) d\left(x_{n}, p\right)$

$\leq b_{n}+t_{n} a_{n}+t_{n} s_{n} d\left(T^{n} x_{n}, p\right)+t_{n}\left(1-s_{n}\right) d\left(x_{n}, p\right)+t_{n} c_{n}+\left(1-t_{n}\right) d\left(x_{n}, p\right)$

$\leq b_{n}+t_{n} a_{n}+t_{n} s_{n}\left[d\left(x_{n}, p\right)+c_{n}\right]+t_{n}\left(1-s_{n}\right) d\left(x_{n}, p\right)+t_{n} c_{n}+\left(1-t_{n}\right) d\left(x_{n}, p\right)$

$=b_{n}+t_{n} a_{n}+t_{n} c_{n}+t_{n} s_{n} c_{n}+d\left(x_{n}, p\right)$

$\leq b_{n}+a_{n}+2 c_{n}+d\left(x_{n}, p\right)$,

which by $\sum_{n=1}^{\infty} a_{n}<\infty, \sum_{n=1}^{\infty} b_{n}<\infty, \sum_{n=1}^{\infty} c_{n}<\infty$ and Lemma 1.13 implies $\lim _{n \rightarrow \infty} d\left(x_{n}, p\right)$ exists.

Lemma 2.3. Let $X$ be a complete $C A T(0)$ space, $C$ be a nonempty, bounded, closed and convex subset of $X$ and $T: C \rightarrow C$ be a continuous mapping of asymptotically nonexpansive type. Put

$$
c_{n}=\max \left\{0, \sup _{x, y \in C}\left\{d\left(T^{n} x, T^{n} y\right)-d(x, y)\right\}\right\} .
$$

Suppose $\sum_{n=1}^{\infty} c_{n}<\infty,\left\{x_{n}\right\}$ is given by definition 2.1 such that $\left\{t_{n}\right\}$ is in $[a, b]$ for some $a, b \in(0,1)$ and $\lim \sup _{n \rightarrow \infty} s_{n}<1$. Then, 


$$
\lim _{n \rightarrow \infty} d\left(x_{n}, T x_{n}\right)=0 .
$$

Proof. By Lemma 1.8, let $p \in F(T)$. It follows from Lemma 2.2 that $\lim _{n \rightarrow \infty} d\left(x_{n}, p\right)$ exists. Let $\lim _{n \rightarrow \infty} d\left(x_{n}, p\right)=r$. We have $d\left(T^{n} y_{n}, p\right) \leq d\left(y_{n}, p\right)+c_{n} \leq d\left(y_{n}, u_{n}\right)+d\left(u_{n}, p\right)+c_{n}$

$\leq a_{n}+s_{n} d\left(T^{n} x_{n}, p\right)+\left(1-s_{n}\right) d\left(x_{n}, p\right)+c_{n}$

$\leq a_{n}+s_{n} d\left(x_{n}, p\right)+s_{n} c_{n}+\left(1-s_{n}\right) d\left(x_{n}, p\right)+c_{n}$

$=a_{n}+c_{n}+s_{n} c_{n}+d\left(x_{n}, p\right)$.

$\leq a_{n}+2 c_{n}+d\left(x_{n}, p\right)$.

By $\lim _{n \rightarrow \infty}\left(a_{n}+2 c_{n}\right)=0$, we obtain,

$$
\limsup _{n \rightarrow \infty} d\left(T^{n} y_{n}, p\right) \leq \limsup _{n \rightarrow \infty} d\left(x_{n}, p\right)=r .
$$

On the other hand, $\quad\left|d\left(x_{n+1}, p\right)-d\left(v_{n}, p\right)\right| \leq b_{n} \quad$ and $\quad b_{n} \rightarrow 0$ imply

$$
\lim _{n \rightarrow \infty} d\left(t_{n} T^{n} y_{n} \oplus\left(1-t_{n}\right) x_{n}, p\right)=\lim _{n \rightarrow \infty} d\left(v_{n}, p\right)=\lim _{n \rightarrow \infty} d\left(x_{n+1}, p\right)=r .
$$

Hence, by Lemma 1.14, $\lim _{n \rightarrow \infty} d\left(x_{n}, T^{n} y_{n}\right)=0$. Moreover, $d\left(x_{n}, T^{n} x_{n}\right) \leq d\left(x_{n}, T^{n} y_{n}\right)+d\left(T^{n} y_{n}, T^{n} x_{n}\right)$

$\leq d\left(x_{n}, T^{n} y_{n}\right)+d\left(y_{n}, x_{n}\right)+c_{n}$

$\leq d\left(x_{n}, T^{n} y_{n}\right)+d\left(y_{n}, u_{n}\right)+d\left(u_{n}, x_{n}\right)+c_{n}$

$\leq d\left(x_{n}, T^{n} y_{n}\right)+a_{n}+s_{n} d\left(T^{n} x_{n}, x_{n}\right)+c_{n}$.

Therefore,

$$
d\left(x_{n}, T^{n} x_{n}\right) \leq \frac{d\left(x_{n}, T^{n} y_{n}\right)+a_{n}+c_{n}}{1-s_{n}},
$$

which by $\lim \sup _{n} s_{n}<1, a_{n} \rightarrow 0, c_{n} \rightarrow 0$ and $d\left(x_{n}, T^{n} y_{n}\right) \rightarrow 0$, implies

$$
\lim _{n \rightarrow \infty} d\left(x_{n}, T^{n} x_{n}\right)=0 .
$$

In addition,

$d\left(x_{n}, T x_{n}\right) \leq d\left(x_{n}, x_{n+1}\right)+d\left(x_{n+1}, T^{n+1} x_{n+1}\right)+d\left(T^{n+1} x_{n+1}, T^{n+1} x_{n}\right)+d\left(T^{n+1} x_{n}, T x_{n}\right)$

$\leq d\left(x_{n}, x_{n+1}\right)+d\left(x_{n+1}, T^{n+1} x_{n+1}\right)+d\left(x_{n+1}, x_{n}\right)+c_{n+1}+d\left(T^{n+1} x_{n}, T x_{n}\right)$ 
$=2 d\left(x_{n}, x_{n+1}\right)+d\left(x_{n+1}, T^{n+1} x_{n+1}\right)+c_{n+1}+d\left(T^{n+1} x_{n}, T x_{n}\right)$

$\leq 2 d\left(x_{n}, v_{n}\right)+2 d\left(v_{n}, x_{n+1}\right)+d\left(x_{n+1}, T^{n+1} x_{n+1}\right)+c_{n+1}+d\left(T^{n+1} x_{n}, T x_{n}\right)$

$\leq 2 t_{n} d\left(x_{n}, T^{n} y_{n}\right)+2 b_{n}+d\left(x_{n+1}, T^{n+1} x_{n+1}\right)+c_{n+1}+d\left(T\left(T^{n} x_{n}\right), T x_{n}\right)$.

Hence, by $b_{n} \rightarrow 0, c_{n} \rightarrow 0, d\left(x_{n}, T^{n} y_{n}\right) \rightarrow 0, d\left(x_{n}, T^{n} x_{n}\right) \rightarrow 0$ and the uniform continuity of $T$, we conclude

$$
\lim _{n \rightarrow \infty} d\left(x_{n}, T x_{n}\right)=0
$$

Theorem 2.4. Let $X$ be a complete $C A T(0)$ space, $C$ be a nonempty, bounded, closed and convex subset of $X$ and $T: C \rightarrow C$ be a continuous mapping of asymptotically nonexpansive type. Put

$$
c_{n}=\max \left\{0, \sup _{x, y \in C}\left\{d\left(T^{n} x, T^{n} y\right)-d(x, y)\right\}\right\} .
$$

Suppose $\sum_{n=1}^{\infty} c_{n}<\infty,\left\{x_{n}\right\}$ is given by definition 2.1 such that $\left\{t_{n}\right\}$ is in $[a, b]$ for some $a, b \in(0,1)$, and $\limsup _{n \rightarrow \infty} s_{n}<1$. Then $\left\{x_{n}\right\}$ is $\Delta$-convergent to a fixed point of $T$.

Proof. By Lemma 2.2, $\left\{d\left(x_{n}, p\right)\right\}$ is convergent for all $p \in F(T)$ and Lemma 2.3 implies $\lim _{n \rightarrow \infty} d\left(x_{n}, T x_{n}\right)=0$. Therefore, by Lemma 1.12, $\omega_{w}\left(x_{n}\right)$ consists exactly one point and is a subset of $F(T)$. This shows that $\left\{x_{n}\right\}$ is $\Delta$-convergent to an element of $F(T)$.

Theorem 2.5. Let $X$ be a complete $C A T(0)$ space, $C$ be a nonempty compact convex subset of $X$ and $T: C \rightarrow C$ be a continuous mapping of asymptotically nonexpansive type. Put

$$
c_{n}=\max \left\{0, \sup _{x, y \in C}\left\{d\left(T^{n} x, T^{n} y\right)-d(x, y)\right\}\right\} .
$$

If $\sum_{n=1}^{\infty} c_{n}<\infty,\left\{x_{n}\right\}$ is given by definition 2.1 such that $\left\{t_{n}\right\}$ is in $[a, b]$ for some $a, b \in(0,1)$, and $\limsup _{n \rightarrow \infty} s_{n}<1$, then $\left\{x_{n}\right\}$ converges strongly to $a$ fixed point of $T$.

Proof. By compactness of $C,\left\{x_{n}\right\}$ has a subsequence $\left\{x_{n_{k}}\right\}$ such that $\left\{x_{n_{k}}\right\}$ converges strongly to an element in $C$. Let $\lim _{k} x_{n_{k}}=z$, then

$d(z, T z) \leq d\left(z, x_{n_{k}}\right)+d\left(x_{n_{k}}, T x_{n_{k}}\right)+d\left(T x_{n_{k}}, T z\right) \leq 2 d\left(z, x_{n_{k}}\right)+d\left(x_{n_{k}}, T x_{n_{k}}\right)$.

By Lemma 2.3, $d\left(x_{n_{k}}, T x_{n_{k}}\right) \rightarrow 0$ and $\lim _{k} x_{n_{k}}=z$, we obtain

$$
d(z, T z)=0
$$


which implies $z \in F(T)$. Therefore, Lemma 2.2 and $\lim _{k} d\left(x_{n_{k}}, z\right)=0$ imply

$$
\lim _{n} d\left(x_{n}, z\right)=0
$$

Hence, $\left\{x_{n}\right\}$ converges strongly to $z \in F(T)$.

\section{References}

[1] Bridson, M. and Haefliger, A., Metric Spaces of Non-Positive Curvature, vol. 319 of Grundlehren der Mathematischen Wissenschaften, Springer, Berlin, Germany, 1999.

[2] Brown, K.S., Buildings, Springer, New York, NY, USA, 1989.

[3] Bruck, R.E., Kuczumow, T. and Reich, S., Convergence of iterates of asymptotically nonexpansive mappings in Banach spaces with the uniform Opial property, Colloqium Math. LXV. 169-179 (1993)

[4] Dhompongsa, S., Kirk, W.A. and Panyanak, B., Nonexpansive set-valued mappings in metric and Banach spaces, J. Nonlinear Convex Anal. 8(1) (2007), pp. 35-45.

[5] Dhompongsa, S., Kirk, W.A. and Sims, B., Fixed points of uniformly Lip-schitzian mappings, Nonlinear Anal. Theory Methods Appl. 65(4) (2006), pp. 762-772.

[6] Dhompongsa, S. and Payanak, B., On $\Delta$-convergence theorems in CAT(0) spaces, Comput. Math. Appl. 56 (2008), pp. 2572-2579.

[7] Geobel, K. and Kirk, W.A., A fixed point theorem for asymptotically nonexpansive mappings, Proc. Amer. Math. Soc. 35 (1972), pp. 171-174.

[8] Goebel, K. and Reich, S., Uniform Convexity, Hyperbolic Geometry, and Nonexpansive Mappings, Monographs and Textbooks in Pure and Applied Mathematics, Marcel Dekker, New York, NY, USA, 83 (1984).

[9] Hussain, N. and Khamsi, M.A., On asymptotic pointwise contractions in metric spaces, Nonlinear Anal. 71 (2009), pp. 4423-4429.

[10] Kirk, W.A., Fixed point theorems for non-Lipschitzian mappings of asymptotically nonexpansive types, Israel J. Math. 17 (1974), pp. 339346.

[11] Kirk, W.A., Fixed point theorems in CAT(0) spaces and $\mathbb{R}$-trees, Fixed Point Theory Appl., vol. 4 (2004), pp. 309-316. 
[12] Kirk, W.A., Geodesic geometry and fixed point theory. II, in International Conference on Fixed Point Theory and Applications, pp. 113-142, Yokohama Publ., 2004.

[13] Kirk, W.A., Geodesic geometry and fixed point theory, in Seminar of Mathematical Analysis (Malaga/Seville, 2002/2003), vol. 64 of Colecc. Abierta, pp.195-225, Universidad de Sevilla Secr. Publ., Seville, Spain, 2003.

[14] Kirk, W.A. and Panyanak, B., A concept of convergence in geodesic spaces, Nonlinear Anal. Theory Methods Appl. 68 (2006), pp. 3689-3696.

[15] Kaczor, W. and Walczuk, J., A mean ergodic theorem for mappings which are asymptotically nonexpansive in the intermediate sense, Nonlinear Anal. Theory Methods Appl. 47 (2001), pp. 2731-2742.

[16] Lim, T.C., Remarks on some fixed point theorems, Proc. Amer. Math. Soc. 60 (1976), pp. 179-182.

[17] Nanjaras, B. and Panyanak, B., Demiclosed principle for asymptotically nonexpansive mappings in $C A T(0)$ spaces, Fixed Point Theory Appl. (2010). (Article ID 268780)

[18] Osilike., M.O. and Aniagbosor, SC., Weak and strong convergence theorems for fixed points of asymptotically nonexpansive mappings, Math. Comput. Modelling, 32 (2000), pp. 1181-1191.

[19] Panyanak, P. and Loakul. T., On the Ishikawa iteration process in CAT(0) spaces, Bull. Iranian Math. Soc., 37 (2011), pp. 185-197.

[20] Rhoades, B.E. and Soltuz, S.M., The equivalence between the convergences of Ishikawa and Mann iterations for an asymptotically nonexpansive in the intermediate sense and strongly successively pseudocontractive maps, J. Math. Anal. Appl. 289 (2004), pp. 266-278.

[21] Schu, j., Weak and strong convergence to fixed of asymptotically nonexpansive mappings, Bull. Australian Math. Soc. 43 (1991), pp. 153-159.

[22] Tan, K.K. and Xu, H.K., Fixed point iteration processes for asymptotically nonexpansive mappings, Proc. Amer. Math. Soc. 122 (2011), pp. 733-739.

[23] Xu, H.K., Existence and convergence for fixed points of mappings of asymptotically nonexpansive type, Nonlinear Anal. Theory Methods Appl. 16 (1991), pp. 1139-1146. 
THE MODIFIED ISHIKAWA ITERATION PROCESS WITH ERRORS IN CAT(0) SPACES

[24] Zhang, J. and Cui, Y., Existence and convergence of fixed points for mappings of asymptotically nonexpansive type in uniformly convex $W$ hyperbolic spaces, Fixed Point Theory Appl. (2011).

Sajad Ranjbar,

Department of Mathematics,

Higher Education Center of Eghlid,

Eghlid, Iran.

Email: sranjbar@eghlid.ac.ir; sranjbar74@yahoo.com 